Journal of Pediatrics Research Reviews \& Reports

\title{
Poisson and Logistics Regression Analysis on Electromagnetic Field Radiation: A Case of Environmental Pollution in Healthcare
}

\section{Iyyanki Muralikrishna1 and Prisilla Jayanthi2*}

Former Professor, JNTUH Hyderabad, India

\begin{abstract}
The universal study reveals that Electromagnetic Frequency (EMF) exposure is upsetting the environment. It focuses keenly on the people residing in the neighboring of the base stations / mobile towers were affected by environmental radiation pollution. The effect of EMF radiation on human life is unusually increasing on dayto-day basis. As the number of customers using mobiles rises, one would see the mobile phone towers / base trans-receiver station (BTS) increases; and this has a great and huge impact on radiation hazards. Mobile phones have the capability of emitting radiations that would affect human tissues and it runs a two-way communication paradigm. Radio Frequency (RF) wave establishes communication around the globe in the mobile network. However, the radiations emitted by RF waves are harmful if absorbed into the human tissues. The most side effects experienced when nearer to these towers are headaches, discomfort, anxiety and other diseases. The radiation hazards are found to be extraordinarily more where the cell towers were installed nearer to educational institutes, healthcare and few residential areas. They were recommended to move / stay away from such areas, the radiations can cause tumors, disturbance of the nervous system and other diseases. The study is to understand the radiation exposure limits that would protect the public health from the EMF exposure. RF radiations were mapped by geographic information system (GIS) based measuring approach that helps in detecting places where users are in health hazards in exposed areas. This helps government and health organization to estimate the distribution of radiation in areas nearer to the location of mobile towers. Realization among the people was made to live and spend less time based on the radiation levels of exposure with the mobile towers. The analysis was carried out by STATA software to measure the poisson exposure of confidence interval. The poisson regression calculated for the mobile towers is 47473.38 and -0.00001 for Andhra Pradesh state respectively. Similarly, the poisson exposure is 19.2096 and CI is found to be 0.0013 to 0.2900 in Telangana state of India.
\end{abstract}

Corresponding author: Prisilla Jayanthi, Former Professor, JNTUH Hyderabad, India, Email: prisillaj28@gmail.com

Received: December 20, 2019, Accepted: December 23, 2019, Published: December 31, 2019

Keywords: Poisson Regression, Logistics Regression, Geographical Information System, Electro Magnetic Field, Radiation, Mobile Towers.

\section{Introduction}

The mobility location-based service includes three components, namely Geographic Information System (GIS) technology, position tracking, and visualization. Two ever reliable techniques for identifying and locat- ing various EMF radiation sources are Global Positioning System (GPS) and GIS. GIS-based approach is that which a user utilizes and mobile tower locations to detect the exposure area. The factors that influenced the exposure level includes the frequency of the radiation, 
size and shape; orientation of exposed parts and exposure of duration. GIS is used for procurement, access, and geographically analysis and spatially referenced data. In the location-based services, the tracking of position is a hazardous element. Position tracking includes identification of RF and telemetry technologies. Radiofrequency (RF) identification keeps tracking of object information, such as shipment containers, hazardous resources, or sensitive load. The two forms of location tracking in a mobile are automatic and manual. The systematic process of the mobile device and the wireless network using either GPS or cellular tower triangulation is known as automatic location tracking. However, the manual location tracking is a button click on the mobile apps location.

What is radiation?

The physical region formed by electrically charged objects is termed as EMF. EMF outspreads indefinitely through the space and describes EM interaction and the blend of an electric and magnetic field. The stationary charges generates electric field ' $\mathrm{E}$ ' $[\mathrm{V} / \mathrm{m}]$ whereas, the moving charges produces magnetic field strength ' $\mathrm{H}$ ' $[\mathrm{A} / \mathrm{m}]$. Power density is combined effect of these two fields and denoted by ' $\mathrm{S}$ ' $[\mathrm{W} / \mathrm{m} 2]$. The driving law where the charge and current interact with EMF is coined by Maxwell's equations and Lorentz force law. The key factors in EMF are amplitude, frequency (f), phase, amplitude and wavelength $(\lambda)$ shown in figure 1 . The wavelength is referred as length of the wave measured in meters ( $\mathrm{m}$ ) and is equal to the speed of light (c) divided by its frequency, given by $\lambda=\mathrm{c} / \mathrm{f}$.

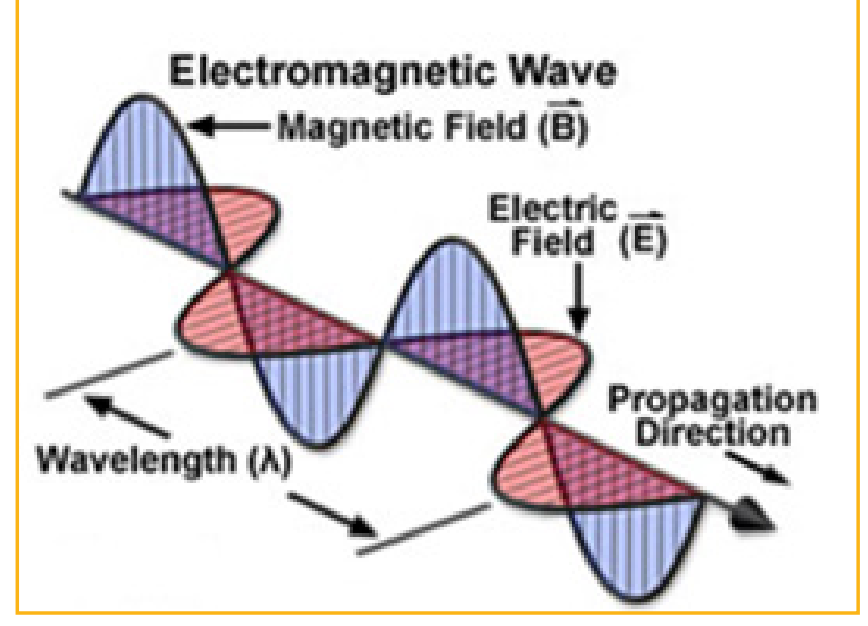

Figure 1: Electromagnetic Wave.
The body exposed to the RF radiation field is the electric and magnetic fields (MF) strength inside the body will be different from the outside. The fields of electric and magnetic are calculated at each body part affected by a particular radiation source such as a mobile phone / towers. The rate, at which the energy is absorbed

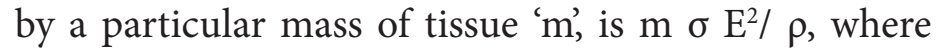
$\sigma$ and $\rho$ are the conductivity and density of the tissue. The power absorbed per mass of tissue is the specific energy absorption rate. SAR quantity is denoted by $\sigma$ $\mathrm{E}^{2} / \rho(\mathrm{W} / \mathrm{kg})$. And it varies from point to point in the body because the electric field changes with position. The EM waves are represented by the self-propagating waves of the components having electric and MFs which oscillate in phase perpendicular to each other and in the direction of the wave propagation. The association between electric and MFs is given by $\mathrm{H}=\mathrm{E} / \mathrm{Z}$, and $\mathrm{Z}$ is the impedance in the free space or vacuum. The World Health Organization (WHO), an agency of the United Nations is the first organization to study about RF field and its impacts on human's health. It is primarily concerned with International public health. WHO established the project because of the high concern on the effect of RF on health, and scientifically indicates that the adverse health effects of the RF.

Emf Radiations on Trees and Other Living Creatures Prisilla and Iyyanki [1] performed a statistically study of meta-analyses for the odd ratios (OR) and confidence interval (CI). The meta-analyses on cases and controls for mobile phones use were performed on Interphone and Hardell study group. The model of heterogeneity test was done on mobile usage for the latency and hours ( $\geq 10$ years and $\geq 1640 \mathrm{~h}$ ). A total of twenty three studies from Interphone and Hardell group were evaluated for glioma patients with number of cases $=35487$ and controls $=82609$. The highest risk was found from the Hardell lower than 20 years of the age group. In a comparative study, OR for the various age groups were obtained by the calculation carried out using review manager on the respective groups' results. Thus, the increased risk for wireless phones are observed to be $\mathrm{OR}=1.032,95 \% \mathrm{CI}=1.019$ to 1.046 [1].

AL-Akhras et al [2] discusses about the environmental pollution caused by cell towers. The study focuses on the people living nearer the base stations or mobile 
towers were affected the most by environmental radiation pollution; and EMF radiation effect was increasing rapidly uncontrollable. The two reliable techniques are GIS and GPS for identifying and localizing the various causes of EMF radiation. The scientific tool named GIS, associates the hardware tools and digital geographic data that require highly sensitive measurement. For minimizing health risk factors caused due to radiation is carried out using GIS mapping system. The graphical representation of high exposure levels in Jordan identifies frequency, intensity, and nonionizing EMF dose that would be harmful to the biosystem and ecosystem. ArcGIS software does 2D and $3 \mathrm{D}$ data mapping. The area under radiation levels are determined by combining GIS data with digital google map from all sites showing radiation levels in different colors using the data obtained. Through this map, areas with high power densities were identified nearer the cell tower very easily. It was also found that few cell towers had higher radiation values comparatively with others. Hence, the Al-Akhras and group argue that due to potential radiation hazards, the existing cell towers nearer institutes, clinics and residential areas must be moved out of such areas. The studies show that radiation levels would cause cancer, miscarriages, disturbance of the nervous system and other diseases [2]. Mild et al in their case study identifies and discusses the approaches on non-ionizing radiation (NIR) such as EMF and optical radiation in Swedish healthcare. In healthcare, NIR is used for diagnoses, therapy and many more applications. The three types where acute effects cannot be ruled out are MRI, transcranial magnetic stimulation and electro surgery. The lasers of class-3 and / or class-4 for optical radiation were used for therapy and surgeries; and ultraviolet light causes unintentional burns, photo reactions, erythema which needs to be avoided. During such treatment by the radiation exposure for patients, the working staff needs to be carefully and control for avoiding acute health effects [3]. Selsam and Eger in other case study showed the impacts of RF-EMF from radar, radio and televisions on trees that proved scientifically. Several researches reported about the impacts on germination, growth and cell metabolism due to radiation. The unilateral crown damage and of premature coloring of leaves, at the beginning on the side facing the antenna, strongly indicates a causal relationship with RF-EMF [4]. In yet other study, Selsam et al analyzed the radiation effect on trees over animals through practical experiments. The study verifies whether there is any association between unusual tree damage and the RF exposure. A detailed monitoring survey was carried out from the year 2006 to 2015 in the cities of Bamberg and Hallstadt (Germany) to understand the radiation effects. The unusual and unexplainable tree damage recordings in photographic form were carried out in the year 2015 with monitoring and observing EM radiation. Both the cities are spanned through a polygon, where 144 readings of the RF-EMF were obtained at a height of $1.5 \mathrm{~m}$ in streets and parks at different locations. A total study was carried out on 60 damaged trees, 30 trees were opted randomly; and 30 trees marked as the polygon from low radiation areas $(n=120)$. The tree readings proved that there is a significant difference between the damaged side facing a tower and the other side of the tree. Thus, this difference in power flux density reading corresponds to damaged side. The consistent result with the fact that the tree damage was found due to mobile towers that started on one side and gradually extended to the whole tree over time [5]. Balmori in their study focused on the impact of RF radiation from wireless telecommunication on wildlife. EMF radiation happens to be an environmental pollution that may offend wildlife. The radiating phone poles located nearer the living areas and are continuously affects some species that suffer in long-term health effects, health deterioration, and reproduction problems. EM radiation can exert different behavioral response in rats, bats and sparrows. This proved that microwave and RF pollution is a possible cause for the decline of animal populations and plants living near mobile towers [6]. Al-Sahly et al in their study on EMF radiation stated that the effects experienced by consumers near these towers are headaches, discomfort, anxiety and other diseases. The study proposes a GIS-based measuring approach that helps to detect RF radiation exposure areas and will map places where users are in dangerexposed areas to health hazards. This approach will help government to calculate radiation in the areas based on the location of mobile towers. Moreover, this will help to understand a hot and green area of mobile tower radiation distributions where the people can 
choose where to live or spend less time based on that exposure level [7].

\section{Emf Radiations using GIS}

Ammoscato et al in their study carried out to realize an infrastructure of measurement, transmissions, elaboration and management of data surveyed for monitoring the EM pollution. The results of a research work showed the realization of a first prototype of advanced system based on the integration of GPS receivers and other sensors. GIS were used create the distribution of EM pollution and accuracy positioning on few thematic maps [8]. In present days, GIS tools are increasing with value adding to the desktops and mobile environment with information in the location context with a specific point. The potential relationships between the data were shown with geo-analysis using GIS technology and data from spatially enabled devices, networks, and applications provide a higher degree of intelligence. This gives overall fundamental understanding of how the location impacts on business and process decisions. Thus, GIS adds a value by giving geographic insight to those who need to make tough decisions regarding a secure homeland [9].

Wagen and Rizk through their study introduced GIS and geographical databases for the measuring and calculating the contours of radiation from the towers. The propagation prediction use and radio network planning of cellular radio communications is carried out. A radio-network planner relies on the user requirement maps, carrier-to-interference ratio, completed calls, rejected calls, etc. The displayed results are overlay for $2 \mathrm{D}$ or $3 \mathrm{D}$ geographical maps, because the geographical locations of consumers are very important in mobile communications areas. The predictions sensitivity with respect to building height is expected to be smaller with accuracy of $1 \mathrm{~m}$. As the buildings effects were greater that were nearer to the mobile towers and near the base station and adaptive accuracy speeds up the predictions computation [10].

Singh et al in their study suggested about GIS that influences the development of rural by providing huge amount of accurate information in timely manner. The elaborations on the factors influencing the establishment of new towers in certain areas were made out of reach. Identifying the areas such as Black Spots was non-existent mobile strength and is carried out by data collection. Through this one can explore that identification of sites for the establishment of cell towers requires data collection, and GIS are used to select the best out of those search rings. The features influencing the cell phone towers installation can be optimized successfully using GIS. This study can be further extended to carry out for establishing the optimization of the strength of mobile network so that maximum request can be served with minimum number of cell towers [11].

\section{Information Gathered From Various Media Sources}

Noida, a state in Uttar Pradesh (India) in Economic Times paper (2015) shown in figure 2 has stated that the specific guidelines for installing telecom towers, and for setting up of a mobile tower, needed a clearance from pollution control board without which a tower would not be setup.

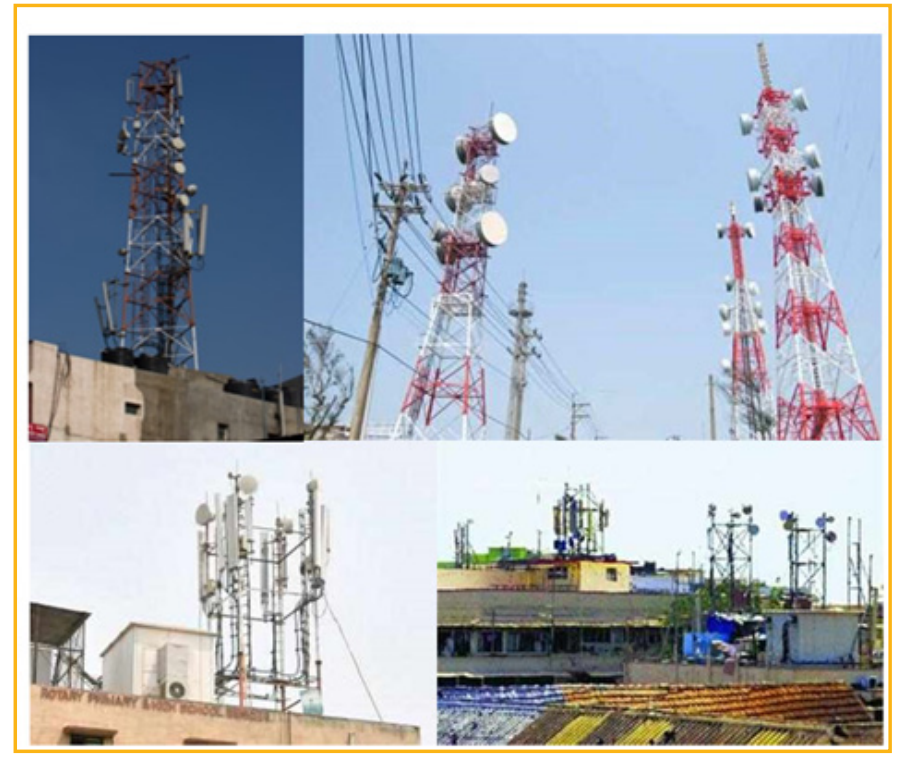

Figure 2: Mobile phone towers in residential areas of Noida (India) Noida Authorities has requested cellphone operators to relocate all towers from the residential areas within a month. The research proposal was called by the government to study the possible impact of EMF radiation on human lives and other living organisms [12]. In yet other case mentioned in The Times of India (2018) in Mysore city in Karnataka state (India) where the installation of mobile towers near schools, residential areas and hospitals was the biggest issues faced by the city residents. They ensured that the mobile towers were installed in open spaces and commercial areas 
[13]. In Mumbai state (India) in The Hindu paper (2016) mentioned that the state government has recognized the danger posed by mobile towers radiation, and has dispensed comprehensive guidelines for monitoring the radiation. The new norms were framed that includes a safe distance between towers and residential buildings and monitoring the EMF radiations of the towers [14]. But, Mr. Galgali, Advisor, Telecom Regulatory Authority of India (TRAI), Bengaluru in The Hindu paper (2018) expressed the opinion about the on-going research from mobile towers radiations affecting human health, and by the radiations from mobile phones and television's remote control and other electronic devices [15]. The founder of Brightsandz, a Gurugram-based company, Mr. Manas Ganguly added "A cell phone may emit radiation that's 1000 th of the radiation from a cell tower, but holding it next to your ear may cause all the harm" in a statement in The Hindu newspaper $[16,17]$.

\section{Discussions and Results}

The data for the radiation was collected from the www. tarangsanchar.gov.in from 2018 to 2020 . This radiation study was analyzed on the STATA software by finding poisson regression, logistics regression and confidence interval for the two areas under taken. Identifying areas of the mobile tower where more mobile strength was present, the radiation power was considerable more than the distance away from the towers. The logistic regression was calculated for Andhra Pradesh (AP) state and the following table 1 shows the result. In three iterations, the log likelihood was -12.476 in the first and the remaining it was zero for the number of observations equal to 18.

Iteration 0: $\log$ likelihood $=-12.476$

Iteration 1: $\log$ likelihood $=0$

Iteration 2: $\log$ likelihood $=0$

\begin{tabular}{|c|c|}
\hline $\begin{array}{l}\text { Logistic regression } \\
\text { Log likelihood }=0\end{array}$ & $\begin{array}{l}\text { Number of obs }=18 \\
\text { Wald chi2 }(0)= \\
\text { Prob }>\text { chi } 2=\end{array}$ \\
\hline $\begin{array}{l}\text { MWP } \\
\text { DPL: } 73.327\end{array}$ & $\begin{array}{lll}\text { Coef. S E } & \mathrm{z} & \mathrm{P}>|\mathrm{z}| \\
{[95 \% \mathrm{Cl}]} & & \end{array}$ \\
\hline & $\begin{array}{lll}- & - & -\end{array}$ \\
\hline
\end{tabular}

Table 1: Logistics regression for the year 2018- 2020 (AP) .

The confidence interval calculated between the dependent (Measured-value-Watt-per-meter (MWP)) and independent variable (DoT-Prescribed-Limit $(\mathrm{DPL})$ ) and poisson exposure variable is DPL was shown in table 2.

\begin{tabular}{|l|l|l|l|l|}
\hline Var. & $\begin{array}{l}\text { Expo- } \\
\text { sure }\end{array}$ & Mean & S E & $95 \%$ CI \\
\hline MWP & 47473.38 & 0 & 0 & $\begin{array}{l}0 \text { to } \\
0.00007\end{array}$ \\
\hline
\end{tabular}

Table 2: Confidence Interval for the year 2018- 2020 (AP).

The poisson regression calculated between the dependent and independent variable is as follows in the table 3, where for the first iteration the log likelihood was -2.4586579 and the next iteration had -2.4586578 . The contour plots for the Andhra Pradesh and Telangana states are shown in figure 3.

Iteration 0: $\log$ likelihood $=-2.458$

Iteration 1: $\log$ likelihood $=-2.458$

\begin{tabular}{|c|c|c|c|c|c|}
\hline \multicolumn{3}{|c|}{ Poisson regression } & \multicolumn{3}{|c|}{ Number of observation $=91$} \\
\hline \multicolumn{6}{|c|}{$\operatorname{LR} \operatorname{chi} 2(1)=0.00$} \\
\hline \multicolumn{6}{|c|}{ Prob $>$ chi $2=0.974$} \\
\hline \multicolumn{3}{|c|}{ Log likelihood $=-2.458$} & \multicolumn{2}{|c|}{ Pseudo R2 } & $=0.0002$ \\
\hline MWP & Coef. & S E & $\mathrm{z}$ & $\mathrm{P}>|\mathrm{z}|$ & $95 \% \mathrm{CI}$ \\
\hline DPL & -0.00001 & 0.00041 & -0.03 & 0.977 & $\begin{array}{l}-0.0008 \\
\text { to } \\
0.0007\end{array}$ \\
\hline $\begin{array}{l}\text { Con- } \\
\text { stant }\end{array}$ & -5.3651 & 1.5413 & -3.48 & 0.001 & $\begin{array}{l}-8.3862 \\
\text { to } \\
-2.3440\end{array}$ \\
\hline
\end{tabular}

Table 3: Poisson regression for the year 2018- 2020 (AP).

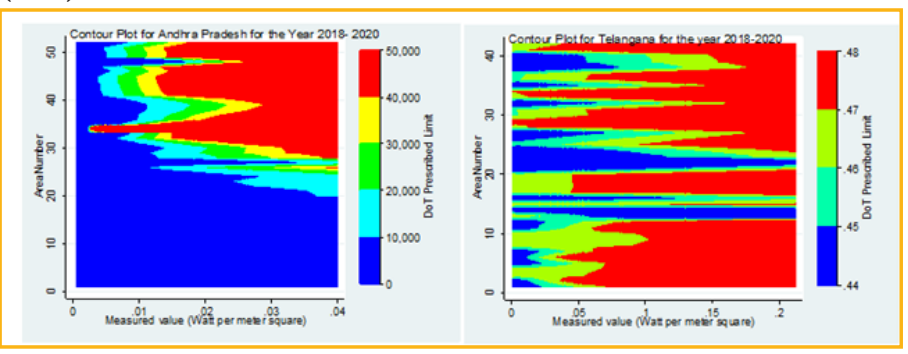

Figure 3: Contour Plots for the year 2018- 2020 for Andhra Pradesh and Telangana states in India.

The logistic regression was calculated for Telangana (TS) state and the following table 4 shows the result. In three iterations the log likelihood was -12.476649 in the first and the remaining it was zero for the number of observations equal to 18 . 
Iteration 0: $\log$ likelihood $=-12.4766$

Iteration 1: $\log$ likelihood $=0$

teration 2: $\log$ likelihood $=0$

\begin{tabular}{|c|c|}
\hline $\begin{array}{l}\text { Logistic regression } \\
\text { Log likelihood }=0\end{array}$ & $\begin{array}{l}\text { Number of observation } \\
=\quad 18 \\
\text { Wald chi } 2(0)= \\
\text { Prob }>\text { chi } 2=\end{array}$ \\
\hline $\begin{array}{l}\text { MWP } \\
\text { DPL: } 74.0445\end{array}$ & $\begin{array}{llll}\text { Coef. S E } & \mathrm{z} & \mathrm{P}>|\mathrm{z}| \\
{[95 \%} & \mathrm{CI}]\end{array}$ \\
\hline & $\begin{array}{llllll}- & - & - & - & & -\end{array}$ \\
\hline
\end{tabular}

The confidence interval calculated between the dependent (MWP) and independent variable (DPL) and poisson exposure variable is DPL was shown in table 5 .

\begin{tabular}{|l|l|l|l|l|}
\hline Var. & $\begin{array}{l}\text { Expo- } \\
\text { sure }\end{array}$ & Mean & S E & $95 \%$ CI \\
\hline MWP & 19.2096 & 0.0520 & 0.0520 & $\begin{array}{l}0.0013 \\
\text { to } \\
0.2900\end{array}$ \\
\hline
\end{tabular}

The Poisson regression calculated between the dependent and independent variable is as follows in the table 6, where for the first iteration the log likelihood was -8.3352349 and the next iteration had -8.3352348 .

\begin{tabular}{|c|c|c|c|c|c|}
\hline \multicolumn{3}{|c|}{ Poisson regression } & \multicolumn{3}{|c|}{ Number of observation $=57$} \\
\hline \multicolumn{6}{|c|}{ LR chi2 $(1)=0.09$} \\
\hline \multicolumn{6}{|c|}{ Prob $>$ chi $2=0.7663$} \\
\hline \multicolumn{3}{|c|}{ Log likelihood $=--8.3352348$} & \multicolumn{2}{|c|}{ Pseudo R2 } & $=0.0053$ \\
\hline MWP & Coef. & S E & $\mathrm{z}$ & $\mathrm{P}>|\mathrm{z}|$ & $95 \% \mathrm{CI}$ \\
\hline DPL & 14.8508 & 51.3752 & 0.29 & 0.773 & $\begin{array}{l}-85.8427 \\
\text { to } \\
115.5445\end{array}$ \\
\hline constant & -10.0750 & 23.7618 & -0.42 & 0.672 & $\begin{array}{l}-56.6474 \\
\text { to } \\
36.4973\end{array}$ \\
\hline
\end{tabular}

Table 6: Poisson regression for the year 2018- 2020 (TS)

In the figure 4, the GIS mapping of the mobile towers is shown for the two areas that were undertaken for study. The dots represents the mobile towers.

In the figure 4, the GIS mapping of the mobile towers is shown for the two areas that were undertaken for study. The dots represents the mobile towers.

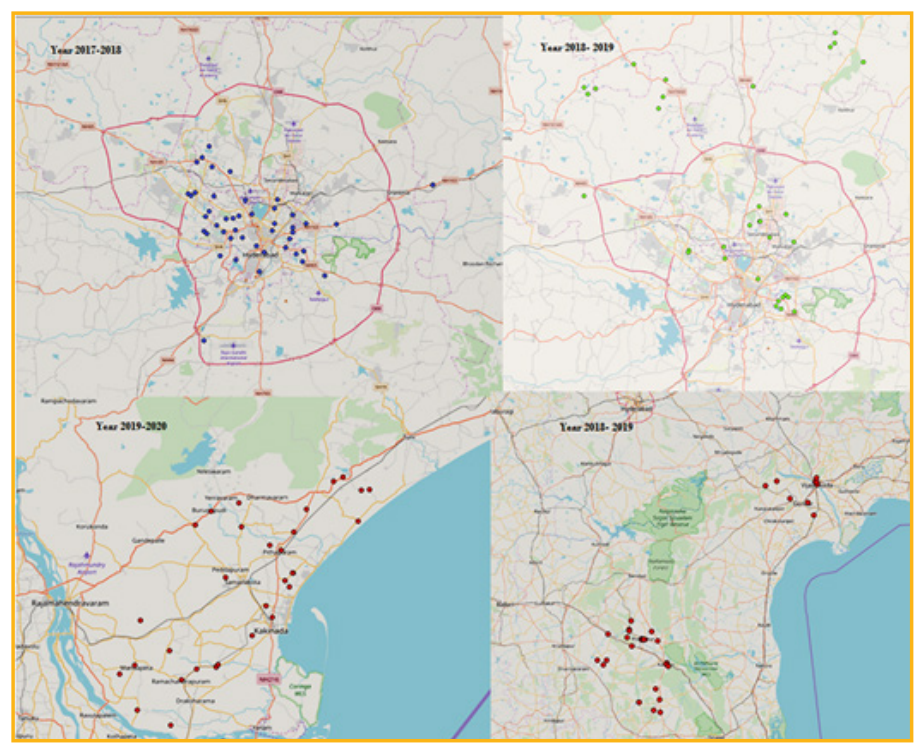

Figure 4: GIS mapping of mobile towers in the year 2017- 2018 and 2018- 2019 in Telangana and year 2018 - 2019 and 2019 to 2020 in Andhra Pradesh. Few mobile towers are observed to be very close to residential and commercial areas; some are very close to institutions and clinics where large numbers of people move about. This indicates clearly that at the time of tower installation no objection was raised in such areas where the pictures were taken as shown in figure 5 . The people unknowingly are ignoring the facts of health risk associated with the mobile towers for the long-term risk.

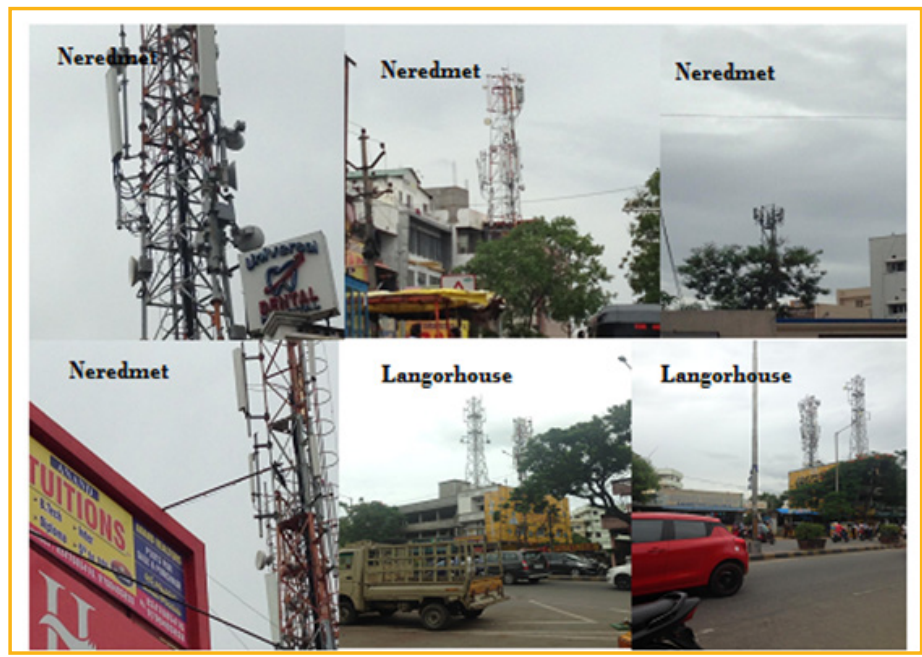

Figure 5: Mobile towers very close to residential / commercial areas in Hyderabad (India).

Thus from the above analysis one can understand the radiation power is more near the towers than the radiative power when moved / living away from the tower. Hence to establish a particular cell tower, a telecom company faces a lot of challenges. 
A number of studies suggest that the effects of RF fields are noticed on brain electrical activity, cognitive function, sleep, heart rate and blood pressure in any individual human.

\section{Conclusions}

Epidemiological research states that a potential longterm risk from RF exposure is likely to be associated between brain tumors / cancers and mobile phone / towers. From the study on EMF produced from the mobile towers; the maximum radiation level was observed at Samalkot, Kakinada (AP) was 0.0139 W/ $\mathrm{m} 20.1071 \mathrm{~W} / \mathrm{m} 2$ in Banjara Hills (TS) and Vijayawada was $0.03992 \mathrm{~W} / \mathrm{m} 2$ (AP) and $0.2122 \mathrm{~W} / \mathrm{m} 2$ (TS) in Chaitanyapuri, Dilsukhnagar which are the most populated cities. The poisson exposure of confidence interval and poisson regression calculated for the mobile towers is 47473.38 and -0.000019 for AP state respectively. Similarly, the poisson exposure is 19.2096 and CI was found to be 0.0018 to 0.2900 for TS state.

\section{References}

1. Prisilla, Iyyanki, (2019) "Statistical analysis of mobile radiation and impact on health: A case study on occurrence of brain tumors", EPH - International Journal of Medical and Health Science 5.

2.MH Al-Akhras (2015) "Environmental Pollution of Cell-Phone Towers: Detection and Analysis Using Geographic Information System", Jordan Journal of Earth and Environmental Sciences 7: 77-85.

3. KH Mild (2019) "Non-ionizing Radiation in Swedish Health Care-Exposure and Safety Aspects", Int J Environ Res Public Health 16: 1186.

4.CWSelsam,HEger,(2013) “Treedamagesinthevicinity of mobile phone base stations", kompetenzinitiative. net/KIT/wp-content/uploads/2016/06/Tree-damagesin-the-vicinity-of-mobile-phone-base-stations.

5. C W Selsam (2016) "Radiofrequency radiation injures trees around mobile phone base stations", Science of the Total Environment 572: 554-569.

6. A Balmori (2009) "Electromagnetic pollution from phone masts. Effects on wildlife", Pathophysiology 16: 191-199.

7. A Al-Sahly (2018) "Using GIS for Measuring Mobile Tower Radiation on Human".

8. A Ammoscato (2008) "GPS-GIS integrated system for electromagnetic pollution", The International Archives of the Photogrammetry, Remote Sensing and Spatial Information Sciences, Beijing 37.

9. "Mobile GIS for Homeland Security" ESRI White Paper www.esri.com/homelandsecurity.

10.J Wagen, K Rizk, (2003) "Radiowave propagation, building databases, and GIS: anything in common? A radio engineer's viewpoint", Environment and Planning B: Planning and Design 30: 767-787.
11. C Singh (2016) "Analysis and Identification of Potential Cell Tower Sites using GIS", International Journal of Scientific \& Engineering Research 2.

12. Shrinivasa M "Citizens don't want telecom towers in residential areas", https://timesofindia.indiatimes.com/ city/mysuru/citizens-dont-want-telecom-towers-inresidential-areas/articleshow $/ 63778224 . \mathrm{cms}$.

13. "Noida activists demand green clearance for mobile towers", https://telecom.economictimes.indiatimes. $\mathrm{com} /$ news/infrastructure/towers/noida-activistsdemand-green-clearance-for-mobile-towers/46016625. 14."Finally, rules to govern mobile tower radiation", https://www.thehindu.com/news/cities/mumbai/ Finally-rules-to-govern-mobile-tower-radiation/ article16076169.ece\#.

15. Shreenivas SG "TRAI: No scientific proof so far that mobile tower radiation is a health risk", https:// www.thehindu.com/news/national/karnataka/trai-noscientific-proof-so-far-that-mobile-tower-radiation-isa-health-risk/article24971836.ece.

16.Lesley simeon "How to track radiation pollution", https://www.thehindu.com/life-and-style/homes-andgardens/how-to-track-radiation-exposure-in-yourfood-at-home-and-on-the-streets/article26025899.ece. 17. www.tarangsanchar.gov.in.

Copyright: (C2019 Prisilla Jayanthi. This is an openaccess article distributed under the terms of the Creative Commons Attribution License, which permits unrestricted use, distribution, and reproduction in any medium, provided the original author and source are credited. 